\title{
Potential Risk Factors for Nivolumab-induced Thyroid Dysfunction
}

\author{
HARUHIKO YAMAZAKI ${ }^{1}$, HIROYUKI IWASAKI $^{1}$, TOSHINARI YAMASHITA $^{1}$, TATSUYA YOSHIDA $^{1}$, \\ NOBUYASU SUGANUMA ${ }^{1}$, TAKASHI YAMANAKA ${ }^{1}$, KATSUHIKO MASUDO $^{2}$, \\ HIROTAKA NAKAYAMA ${ }^{3}$, KAORI KOHAGURA ${ }^{3}$, YASUSHI RINO ${ }^{3}$ and MUNETAKA MASUDA ${ }^{3}$ \\ ${ }^{I}$ Department of Breast and Endocrine Surgery, Kanagawa Cancer Center, Yokohama, Japan; \\ ${ }^{2}$ Department of Breast and Thyroid Surgery, \\ Yokohama City University Medical Center Minamiku, Yokohama, Japan; \\ ${ }^{3}$ Department of Surgery, Yokohama City University School of Medicine, Yokohama, Japan
}

\begin{abstract}
Background: Thyroid dysfunction is occasionally reported after the administration of nivolumab. We report on the incidence of and risk factors for nivolumab-induced thyroid dysfunction in patients with non-small lung cancer. Patients and Methods: A total of 82 patients who received nivolumab between January 2016 and December 2016 at the Kanagawa Cancer Center were included. Prior to nivolumab treatment, 72 patients had normal thyroid function. Results: Among the 72 patients with normal thyroid function prior to nivolumab treatment, the incidence of thyroid dysfunction was $19.5 \%$. There were no significant differences between patients in whom thyroid dysfunction had occurred regarding sex, age, nivolumab dose, or thyroid function prior to nivolumab administration. However, the total number of doses of nivolumab was significantly greater in patients who developed thyroid dysfunction after nivolumab treatment $(p=0.03)$. Conclusion: The total number of doses administered may be a risk factor for the development of thyroid dysfunction after nivolumab therapy.
\end{abstract}

Nivolumab is an monoclonal antibody specific for programmed cell death-1 (PD-1) that is used in the treatment of cancer such as malignant melanoma, non-small cell lung cancer (NSCLC), renal cell cancer, and Hodgkin's lymphoma. Thyroid dysfunction, including hypothyroidism

This article is freely accessible online.

Correspondence to: Haruhiko Yamazaki, Department of Breast and Endocrine Surgery, Kanagawa Cancer Center, 2-3-2 Nakao, Asahiku, Yokohama, Kanagawa, Japan. Tel: +81 455202222, Fax: +81 455202202, e-mail: h.yamazaki0413@kcch.jp

Key Words: Thyroid, nivolumab, immunotherapy. and hyperthyroidism, is occasionally reported after the administration of nivolumab. However, the association between thyroid dysfunction and nivolumab remains unclear. In this retrospective study, we report on the incidence of and risk factors for thyroid dysfunction following nivolumab treatment.

\section{Materials and Methods}

Eighty-two patients who received nivolumab between January 2016 and December 2016 at Kanagawa Cancer Center were included. Baseline patient characteristics are shown in Table I. All patients had a diagnosis of NSCLC. Prior to nivolumab treatment, 72 patients had normal thyroid function, seven had subclinical hypothyroidism, defined as an elevated thyrotropin level with free thyroxine level within the reference range, and three had subclinical hyperthyroidism, defined as an decreased thyrotropin (TSH) level with free thyroxine (F-T4) level within the reference range. In this group, some patients had started treatment with oral levothyroxine prior to the administration of nivolumab. Nivolumab was administered intravenously at $3 \mathrm{mg} / \mathrm{kg}$ once every 2 weeks. Statistical analysis was performed using the Chi-square test and Student's $t$-test.

\section{Results}

Among the 72 patients with normal thyroid function prior to nivolumab treatment, the incidence rate of nivolumabinduced thyroid dysfunction was $15.3 \%$ (11 patients) for hyperthyroidism and subclinical hyperthyroidism, and $4.2 \%$ (3 patients) for hypothyroidism and subclinical hypothyroidism. Among the 10 patients with thyroid dysfunction prior to nivolumab treatment, no patient developed overt thyroid dysfunction after nivolumab treatment. Table II shows patient characteristics, grouped according to whether thyroid dysfunction was observed following nivolumab treatment. No significant differences 
were observed regarding sex, age, nivolumab dose, or thyroid function prior to nivolumab administration between the two groups. However, the total number of doses was significantly greater in patients who developed thyroid dysfunction after nivolumab treatment $(p=0.03)$. Among the 14 patients who developed thyroid dysfunction, the median number of days until thyroid dysfunction was manifested was 81 , with a range of 13 days to approximately 6 months. Three patients required medication for their condition, and all subsequently recovered from their thyroid dysfunction (Table III). Two patients required methimazole treatment for elevated free thyroxin. No patient developed overt hypothyroidism, but one patient required levothyroxine treatment for elevated TSH.

\section{Discussion}

In Japan, nivolumab is used for malignant melanoma, which cannot be cured, for non-curable progression or recurrence of NSCLC, unresectable or metastatic renal cell carcinoma, and recurrent or refractory Hodgkin's lymphoma. In this study, all patients had a diagnosis of NSCLC. According to the all examples survey in Japan, nivolumab was administered from the time of approval to 631 patients by March 2015. Thyroid dysfunction was reported in 44 cases. The breakdown was as follows: thyroid dysfunction in 30 cases $(4.8 \%)$, thyroid disorder in five $(0.8 \%)$, hyperthyroidism in five $(0.8 \%)$, goiter in two $(0.3 \%)$, thyroiditis in one $(0.2 \%)$, and autoimmune thyroiditis in one case $(0.2 \%)(1)$.

Although thyroid dysfunction caused by nivolumab has been reported, there are many cases of its use in malignant melanoma. In a phase 2 trial of Japanese patients with advanced malignant melanoma, the most frequently occurring drug-related adverse events were free triiodothyronine (F-T3) decrease, F-T4 decrease, and alkaline phosphatase increase (2). The incidence of nivolumabinduced thyroid dysfunction in malignant melanoma is reported to be in the range of 5.6-39\% (3-5). In our study, only patients with NSCLC were included, and the incidence of thyroid dysfunction was approximately $20 \%$. Therefore, this suggests that thyroid dysfunction caused by nivolumab might not depend on the target disease.

Dysfunction of the endocrine system by nivolumab may cause adrenal gland dysfunction or pituitary inflammation. A case of eosinophilia and hyponatremia that developed and was diagnosed as pituitary inflammation using magnetic resonance imaging has been reported (6). Therefore, hypothyroidism associated with decreased pituitary function may also develop. When differentiation is required, adrenocorticotropin and cortisol measurement, pituitary gland imaging, and magnetic resonance imaging are also considered. In this study, hyperthyroidism and subclinical hyperthyroidism $(15.3 \%)$ were more frequent than
Table I. Baseline patient characteristics.

\begin{tabular}{lc}
\hline Characteristic & $\mathrm{n}=82$ \\
\hline Gender & \\
$\quad$ Male & $56(68 \%)$ \\
Female & $26(32 \%)$ \\
Median age (range) & $66.5(46-84)$ years \\
Median single dose (range) & $180(107-240) \mathrm{mg}$ \\
Median total number of doses (range) & $4(1-22)$ \\
Normal thyroid function, $\mathrm{n}(\%)$ & $72(87.8 \%)$ \\
Subclinical hypothyroidism, $\mathrm{n}(\%)$ & $7(8.5 \%)$ \\
Subclinical hyperthyroidism, n $(\%)$ & $3(3.7 \%)$ \\
Thyroid function & \\
Median TSH (range) & $1.46(0.04-99.69) \mathrm{mlU} / \mathrm{ml}$ \\
Median F-T3 (range) & $2.71(1.42-3.62) \mathrm{pg} / \mathrm{ml}$ \\
Median F-T4 (range) & $1.09(0.48-1.50) \mathrm{ng} / \mathrm{ml}$ \\
\hline
\end{tabular}

TSH: Thyrotropin, F-T3: free triiodothyronine, F-T4: free thyroxine.

Table II. Characteristics of patients with normal thyroid function prior to nivolumab treatment.

\begin{tabular}{lccc}
\hline Characteristic & $\begin{array}{c}\text { Thyroid } \\
\text { dysfunction } \\
(\mathrm{n}=14)\end{array}$ & $\begin{array}{c}\text { No thyroid } \\
\text { dysfunction } \\
(\mathrm{n}=58)\end{array}$ & $p$-Value \\
& & & \\
\hline Gender & $7(50 \%)$ & $39(67.2 \%)$ & 0.23 \\
Male & $7(50 \%)$ & $19(32.8 \%)$ & \\
Female & $64(46-71)$ & $66(46-84)$ & 0.29 \\
Median age (range) & 183.5 & 176.5 & 0.36 \\
Median single dose (mg) & $8(2-18)$ & $4(1-22)$ & 0.03 \\
Median total number & & & 0.47 \\
of doses (range) & $1.35 \mathrm{mlU} / \mathrm{ml}$ & $1.46 \mathrm{mlU} / \mathrm{ml}$ & 0.30 \\
Thyroid function & $2.82 \mathrm{pg} / \mathrm{ml}$ & $2.71 \mathrm{pg} / \mathrm{ml}$ & 0.30 \\
$\begin{array}{l}\text { Median TSH } \\
\text { Median F-T3 }\end{array}$ & $1.08 \mathrm{ng} / \mathrm{ml}$ & $1.09 \mathrm{ng} / \mathrm{ml}$ & 0.80 \\
\hline Median F-T4 & & & \\
\hline
\end{tabular}

TSH: Thyrotropin, F-T3: free triiodothyronine, F-T4: free thyroxine.

hypothyroidism and subclinical hypothyroidism (5.6\%). Since patients who developed hypothyroidism after a transient thyrotoxic phase have been reported (7), such cases may have been included.

In general, major adverse events associated with nivolumab treatment occur during the first 6 months after treatment initiation (4). In this study, thyroid dysfunction occurred within this 6-month period. Given that the treatment period of the group that did not develop thyroid dysfunction was approximately only 2 months, the incidence of thyroid dysfunction appears to increase as the treatment period becomes longer. Two cases of subclinical hypothyroidism were reported to have developed overt hypothyroidism after 
Table III. Data of patients who developed overt hyperthyroidism/subclinical hyperthyroidism after nivolumab.

\begin{tabular}{|c|c|c|c|c|c|c|c|}
\hline Case & Age, years & Gender & Total number of doses & Number of days to onset & TRAb & $\mathrm{TgAb}$ & Treatment \\
\hline 1 & 64 & $\mathrm{~F}$ & 3 & 13 & - & + & None \\
\hline 2 & 64 & $\mathrm{~F}$ & 4 & 20 & - & + & Methimazole \\
\hline 3 & 64 & M & 17 & 111 & $\mathrm{NE}$ & $\mathrm{NE}$ & None \\
\hline 4 & 58 & M & 3 & 12 & $\mathrm{NE}$ & $\mathrm{NE}$ & None \\
\hline 5 & 69 & $\mathrm{~F}$ & 12 & 182 & $\mathrm{NE}$ & NE & None \\
\hline 6 & 49 & M & 11 & 57 & - & - & None \\
\hline 7 & 46 & M & 16 & 140 & - & $\mathrm{NE}$ & None \\
\hline 8 & 68 & $\mathrm{~F}$ & 2 & 19 & $\mathrm{NE}$ & $\mathrm{NE}$ & None \\
\hline 9 & 54 & M & 4 & 29 & - & + & Methimazole \\
\hline 10 & 71 & M & 17 & 103 & $\mathrm{NE}$ & $\mathrm{NE}$ & None \\
\hline 11 & 69 & M & 4 & 82 & - & - & None \\
\hline 12 & 56 & $\mathrm{~F}$ & 8 & 80 & $\mathrm{NE}$ & - & None \\
\hline 13 & 67 & $\mathrm{~F}$ & 18 & 155 & $\mathrm{NE}$ & + & Levothyroxine \\
\hline 14 & 68 & $\mathrm{~F}$ & 8 & 126 & $\mathrm{NE}$ & + & None \\
\hline
\end{tabular}

TRAb: Thyrotropin receptor antibody, $\mathrm{TgAb}$ : thyroglobulin antibody, NE: not examined, -: negative, +: positive.

the start of nivolumab treatment (8). However, in this study, among seven patients with subclinical hypothyroidism prior to nivolumab treatment, no patient developed overt hypothyroidism after administration of nivolumab.

There are few reports that discuss antibodies such as the TSH receptor antibody, thyroglobulin antibody, and thyroid peroxidase antibody before and after administration of nivolumab. It will be interesting to see whether thyroid dysfunction is likely to occur in antibody-positive patients and whether the antibodies will be detected prior to the occurrence of thyroid dysfunction. In this study, the antibody was measured only after thyroid dysfunction occurred. Measurement of antibodies before and after administration may make it possible to clarify the mechanism of occurrence of thyroid dysfunction and the risk factors for developing overt thyroid dysfunction. Thyroid dysfunction due to PD-1 inhibitor is frequently observed. However, there are few cases that exhibit severe thyroid dysfunction that is clinically problematic, and nivolumab treatment is often continued (9). Even in this study, although three out of 14 patients required medication for their condition, all subsequently recovered from their thyroid dysfunction.

\section{Conclusion}

Thyroid dysfunction is frequently associated with nivolumab treatment, and the total number of doses may be a risk factor for the development of thyroid dysfunction. Regular measurement of thyroid function is, therefore, necessary during nivolumab treatment, and appropriate treatment of thyroid dysfunction may be required in some cases.

\section{Conflicts of Interest}

None declared.

\section{Acknowledgements}

The Authors are thankful to Editage for assistance in writing this article. The Authors the pulmonologists at Kanagawa Cancer Center for collecting patient data, and Mark Abramovitz, Ph.D., from Edanz Group (www.edanzediting.com/ac), for editing a draft of this article.

\section{References}

1 On thyroid dysfunction in patients treated with opdivo. www.opdivo.jp/contents/pdf/open/koujousenkinou.pdf

2 Deeks ED: Nivolumab: A review of its use in patients with malignant melanoma. Drugs 74: 1233-1239, 2014.

3 Tanaka R, Fujisawa Y, Maruyama H, Nakamura Y, Yoshino K, Ohtsuka $M$ and Fujimoto $M$ : Nivolumab-induced thyroid dysfunction. Jpn J Clin Oncol 46: 575-579, 2016.

4 Topalian SL, Sznol M, McDermott DF, Kluger HM, Carvajal RD, Sharfman WH, Brahmer JR, Lawrence DP, Atkins MB, Powderly JD, Leming PD, Lipson EJ, Puzanov I, Smith DC, Taube JM, Wigginton JM, Kollia GD, Gupta A, Pardoll DM, Sosman JA and Hodi FS: Survival, durable tumor remission, and long-term safety in patients with advanced melanoma receiving nivolumab. J Clin Oncol 32: 1020-1030, 2014.

5 Morganstein DL, Lai Z, Spain L, Diem S, Levine D, Mace C, Gore $\mathrm{M}$ and Larkin J: Thyroid abnormalities following the use of cytotoxic T-lymphocyte antigen- 4 and programmed death receptor protein-1 inhibitors in the treatment of melanoma. Clin Endocrinol 86: 614-620, 2017.

6 Okano Y, Satoh T, Horiguchi K, Toyoda M, Osaki A, Matsumoto S, Tomaru T, Nakajima Y, Ishii S, Ozawa A, Shibusawa N, 
Shimada $\mathrm{T}$, Higuchi $\mathrm{T}$, Chikamatsu $\mathrm{K}$ and Yamada $\mathrm{M}$ : Nivolumab-induced hypophysitis in a patient with advanced malignant melanoma. Endocr J 63: 905-912, 2016.

7 Yamauchi I, Sakane Y, Fukuda Y, Fujii T, Taura D, Hirata M, Hirota K, Ueda Y, Kanai Y, Yamashita Y, Kondo E, Sone M, Yasoda A and Inagaki N: Clinical features of nivolumab-induced thyroiditis: A case series study. Thyroid 27: 894-901, 2017.

8 Narita T, Oiso N, Taketomo Y, Okahashi K, Yamauchi K, Sato M, Uchida S, Matsuda $\mathrm{H}$ and Kawada A: Serological aggravation of autoimmune thyroid disease in two cases receiving nivolmab. J Dermatol 43: 210-214, 2016.
9 Costa R, Carneiro BA, Agulnik M, Rademaker AW, Pai SG, Villaflor VM, Cristofanilli M, Sosman JA and Giles FJ: Toxicity profile of approved anti-PD-1 monoclonal antibodies in solid tumors: a systematic review and meta-analysis of randomized clinical trials. Oncotarget 8: 8910-8920, 2017.

Received September 2, 2017 Revised September 24, 2017 Accepted October 3, 2017 